\title{
Fundamental analysis in the multi-agent trading system
}

\author{
Jerzy Korczak, Marcin Hernes, Maciej Bac \\ Wrocław University of Economics, ul. Komandorska 118/120, 53-345 Wrocław, Poland \\ e-mail: \{jerzy.korczak, marcin.hernes, maciej.bac\}at ue.wroc.pl
}

\begin{abstract}
The paper presents issues related to developing methods for fundamental analysis used to expand capabilities of multi-agent trading system, to better predict the financial market. The fundamental analysis indicators can be used as confirmation of decisions generated by other strategies of the system. The first part of the article discusses briefly the fundamental analysis issues in relation to the online trading on FOREX market. The statistical analysis of correlations of the different time series indicators and algorithms of fundamental analysis agents are examined. The final part discusses the results of the performance evaluation of selected investment strategies, including fundamental-based agents.
\end{abstract}

\section{INTRODUCTION}

$\mathrm{I}_{\mathrm{r}}$ trading support systems, the advices might be computed by one or many algorithms, or by one or many software agents using one or many information sources. An overview of of the agents operating on financial markets has already been given by B. LeBaron [1]. Currently, most trading systems are based on one or only a few algorithms. For example, the solutions described by L. Mendes, P. Godinho and J. Dias [2] use genetic algorithms to perform analysis on the basis of historical quotations. The system described by J.R. Thompson, J.R. Wilson and E. P. Fitts [3] is based on the multifractal time series. In the system described in $[4,5]$ technical analysis indicators are used. There are many solutions based on multi-agent approach. H. C. Aladag, U. Yolco and E. Egrioglu [6] present an evaluation of the portfolio optimisation strategies by three agents: rational agent, interference agent, and technical analysis agent. P. Singh and B. Borah [7] apply a multi-agent system where the agents' intelligence is based on fuzzy expert system. O. Badawy and A. Almotwaly [8] developed the neural networks and neuro-fuzzy computing for taking into account the geometrical patterns of the financial data. M. Aloud, E.P.K. Tsang and R. Olsen [9] introduce an agent-based model for simple prediction of financial markets, where each agent predicts the development of selected subsets of the assets pairs in real time by separately examining the similarities between ask and bid assets histories. P. Kaltwasser [10] describes an agent that uses multiple behavioral techniques to make bidding decisions in the face of market uncertainty. J. Glattfelder, A. Dupuis and R. Olsen [11] develop a system that supports multiple strategies, but they use only movingaverage crossover strategies in the current stage of development. The paper by R. Barbosa and O. Belo [12] describes a multi-agent system that consists of a set of trading models such as an ensemble of classifiers, regression models, case-based reasoning, and an expert system. F. H. Westerhoff [13] presents a system where two groups of agents applying the methods of fundamental and technical analysis try to shape market dynamics.

Summing up, more often the trading advice is provide by multiple software agents that use mainly technical analysis. However, many papers related to economic basics [e.g. 14, $15,16]$ state that using a fundamental analysis is also necessary for supporting trading decisions. A few of solutions combine fundamental analysis and behavioral sentiments.

Our platform, called A-Trader [17, 18], allows for the implementation of various algorithms or trading decision support methods [e.g. 19, 20]. The A-Trader is aimed at supporting trading decisions on the FOREX market (Foreign Exchange Market). On FOREX currencies are traded in pairs, for example USD/PLN, EUR/GBP. In general, trader on FOREX can open/close long/short positions. A long position relies on "buying low and selling high" in order to achieve a profit.. A short position, instead, relies on "buying high and selling low". On FOREX, when one currency in a pair is rising in value, the other currency is declining, and vice versa [18]. The A-Trader receives tick data which are aggregated to minute (M1, M5, M15, M30), hour (H1, H4), day (D1), week (W1) and month (MN1). The A-Trader mainly supports High Frequency Trading (HFT) [17], and puts strong emphasis on price formation processes, short-term positions, fast computing, and efficient and robust indicators [19].

High frequency traders seek profits from the market's liquidity imbalances and short-term pricing inefficiencies. Access to quote data must be near real time. Therefore systems supporting trading must provide as soon as possible advice as to which position should be taken: open, close or no entry (do nothing).

The architecture of A-Trader and the description of the different groups of agents have already been detailed [17, 18]. In general, the agents applied technical and behavioral analysis in order to support trading decisions.

The aim of this paper is to present methods for fundamental analysis used to improve the trading efficiency of A-Trader. These methods take into consideration both HFT and also different time resolutions (multiresolution is an integral part 
of A-Trader: from M1 to MN1 periods). Multiresolution is very important issue due to different time periods needed for fundamental analysis on FOREX market. The macroeconomic indicators (e.g. inflation, Gross Domestic Product) are characterized by low fluctuation. (analysis of these indicators is usually performed monthly).

The first part of the article briefly discusses the fundamental analysis issues in relation to the FOREX market. Next, the statistical analysis of correlations of the different time series indicators and algorithms of fundamental analysis agents are examined. The final part discusses the results of the performance evaluation of selected investment strategies, including fundamental- based strategies.

\section{FUNDAMENTAL ANALYSIS ON FOREX MARKET}

The main assumption of fundamental analysis is the notion of equilibrium. At any considered time, a currency pair should trade at a particular rate that balances trade and investment flows. Fluctuations in market risk affect a rate that may be well above or below what financial-economic conditions justify [15]. Unlike technical analysis, fundamental analysis doesn't become less profitable when competition increases. If market dynamics raise interest rates, in consequence a currency will rise proportionately. This cause will not be undone if too many people are aware of it. On the contrary, it will become even stronger [15].

Putting it briefly, FOREX fundamental analysis concerns the following:

1. Driving supply and demand in the market currencies.

2. Economic indicators and asset markets.

3. Indexes.

4. Political and social powers.

There are two major factors affecting the supply and demand balance: interest rates and the state of international trade [22]. Interest rates can have either a strengthening or weakening effect on a particular currency. The high interest rates attract foreign investment, which will strengthen the local currency. Stock market investors often react to interest rate increases by selling off their holdings. How changes in central bank interest rates impact exchange rates are described by following overarching forces: interest rate parity and the carry trade. Emerging (growth) currencies tend to trade in direct proportion to relative interest rate levels, since higher rates attract speculative investors. Recall that investors in the carry trade seek to profit from positive interest rate differentials; hence, the higher the interest rate, the more attractive the corresponding currency [17]. An international trade balance arises if the economy shows a deficit (more imports than exports) which mean that money is flowing out of the country to purchase foreign-made goods, and this may have a devaluing effect on the currency [27]. A decent fundamental analysis comprises the examination of macroeconomic indicators and asset markets, when evaluating a country's currency. Macroeconomic indicators include figures such as $[10,15,16,23]$ :

1) Growth rates, measured by Gross Domestic Product.

2) Inflation.
3) Unemployment.

4) Balance of payments.

5) Market correlations, such as $[16,24]$ :

- gold prices ratio: when gold goes up, the USD often goes down (and vice versa); therefore, an inverse relationship appears between gold and USD ,

- oil prices ratio: the economies of oil-dependent countries weaken as oil prices rise; in such situation a trader can consider buying currencies of commoditybased economies like Australia or Canada or selling oil-dependent currencies.

6) Productivity.

7) Purchasing Managers' Index (PMI), based on new orders, inventory levels, production, supplier deliveries and the employment environment.

Asset markets comprise stocks, bonds and real estate. Other indicators that may be considered are the Consumer Price Index (CPI), Durable Goods Orders, Producer Price Index (PPI), and retail sales.

Index correlations also have influence on currency quotations [25]. Examples of indexes are:

- S\&P 500 is an index which includes the 500 companies with the largest capitalization companies listed on the New York Stock Exchange and NASDAQ,

- FTSE 100 is a share index of the 100 companies listed on the London Stock Exchange with the highest market capitalization,

- WIG index is listed on the Warsaw Stock Exchange; it includes shares listed on the Polish market.

Political considerations impact the level of confidence in a nation's government, the climate of stability and level of certainty [25].

The trading advices generated by agents based on fundamental analysis are used as confirmations of a buy/sell decision suggested by technical analysis-based agents or behavioral-based agents.

\section{COMPARISON OF CORRELATION OF SELECTED} FUNDAMENTAL ANALYSIS FACTORS AND FOREX QUOTATIONS

As was stated in the previous section, the fundamental analysis factors (macro-economic indicators) of a given country are often correlated with its currency quotation.. Fig. 1 presents the example of correlation inflation, oil price, and S\&P 500 index with USD/GBP quotations in 2015 (monthly). On the basis of visual analysis of this chart, we can draw the conclusion that in particular periods most of the macroeconomic indicators are correlated with USD/GBP quotations. For example, taking into consideration the period May-June, the USD/GBP quotations rise and inflation and S\&P 500 also rise (while the oil quotation falls); taking into 
consideration the period November - December, the USD/GBP quotation rises and inflation, S\&P500, and oil also rise.

In order to determine the correlation between these factors, the Mann-Kendall test was used. The non-parametric MannKendall test is commonly employed to detect monotonic trends in series of environmental data, climate data or hydrological data [24]. For two trends correlation a tau Kendall ratio was calculated that counts the number of pairwise disagreements between two time series. The larger the distance, the more dissimilar the two series are [24]. If tau Kendall value is near 1 or -1 , then two time series are correlated, if it is near 0 , then time series are independent.

For example, for the time series presented on Fig 1 (period - 2015 year) tau Kendall correlation values are the following:

- USD/GBP vs. inflation: 0,1,

- USD/GBP vs. oil: - 0.04,

- USD/GBP vs. S\&P500: - 0.2.

According to this metric, the macroeconomic values are not strongly correlated with the USD/GBP quotation, whereas if we look at the chart, they seem to be correlated. This may result from tau Kendall specifics and also from time-shift of the trend change considered quotation and indicators. For example, the USD/GBP quotation starts rising in April, the S\&P500 also in April, but inflation starts rising in May or oil starts rising in March. Therefore, macro-economic indicators can be used mainly for confirmation of long time trends of FOREX quotations.

\section{DESCRIPTION AND EVALUATION OF THE FundAMENTAL ANALYSIS AGENTS}

Input signals of fundamental analysis agents appear with different frequency. One of them is available in high time periods, for example quarterly, monthly, weekly, like the Inflation PPI $\mathrm{M} / \mathrm{M}$, Net Capital Inflows, Change of employment $\mathrm{M} / \mathrm{M}$, and Industrial production.

These signals are very important in establishing and confirming long time trends. According to the rule „Trend is your friend", investing in pursuance of the trend should gain more profits. The Elliott wave theory says that movements in line with the trend are longer and more dynamic. This indicator may be a good advisor in the investment strategy. But it is not enough in the high frequency trading strategy where trades are frequent and positions are opened only for a short time. This indicator can therefore be taken only as advice, not as a signal to open position. The actual macroeconomic situation of the country is the real important indicator. Namely, the main stock exchange indicators such as S\&P500 and FTSE 100 are the main advising factor and trigger for making a trade. Principal goods such as gold and oil are also included, and they usually function as short time indicators.

Neural networks have already demonstrated great potential for discovering non-linear relationships in time-series. The published results of forecasting financial data are particularly good $[21,26,27]$. Therefore, we took the decision to make use of the neural network model as a predictor.

In general, our fundamental analysis agents were built on the Multi-Layer Perceptron model. The diagram of the agent operation is schematically presented in Fig 2. It uses the sigmoid activation function and the back-propagation learning algorithm. Long and short term fundamental indicators were taken into account. The input vector contained the long term indicators and the last sequences of S\&P500, FTSE 100, oil and gold tics. As output, changes in USD/GBP rates were expected. In the learning process, the output values of the neural network were shifted by $T_{n}$ units in time.

The trading strategy of the fundamental analysis agent can be specified as follows:

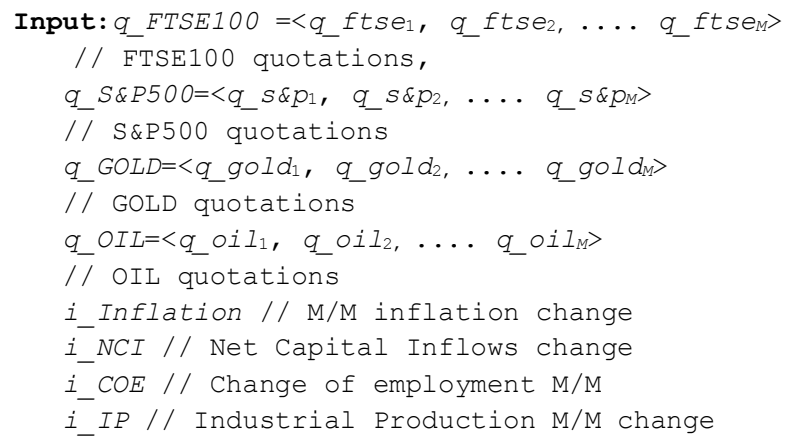

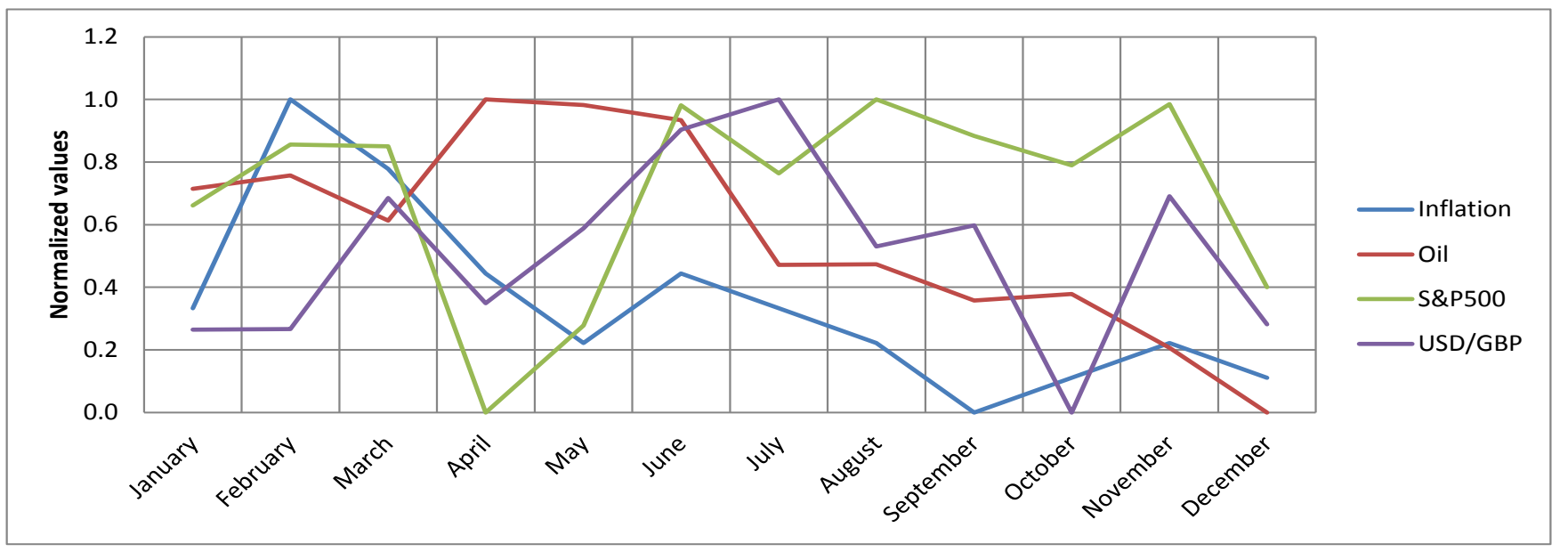

Fig. 1. The example of correlation between inflation, oil prices and S\&P 500 index with USD/GBP quotation in 2015 (monthly). 


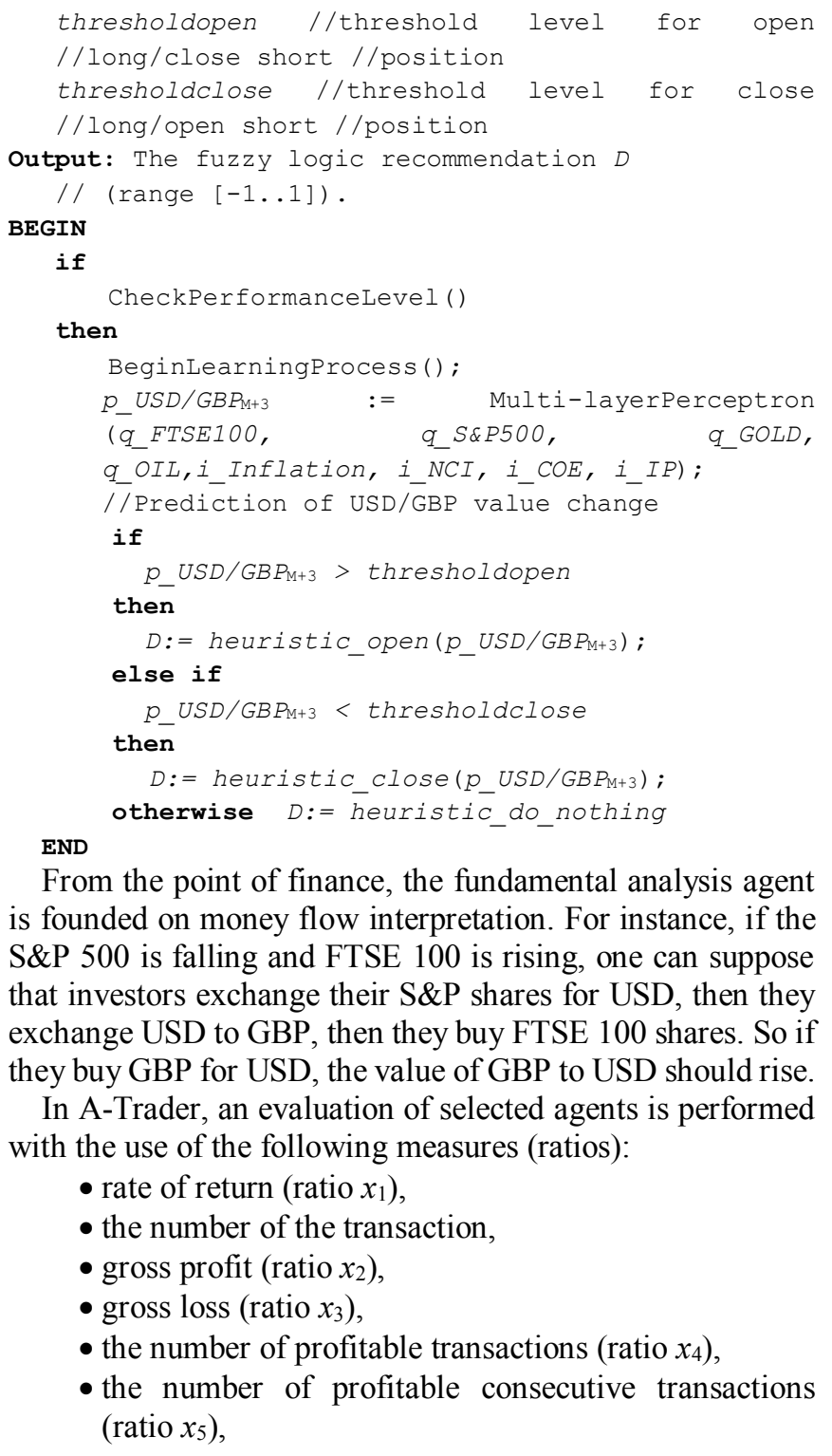

- the number of unprofitable consecutive transactions (ratio $x_{6}$ ),

- Sharpe ratio (ratio $x_{7}$ )

$$
S=\frac{E(r)-E(f)}{|O(r)|} \cdot 100 \%
$$

where:

$E(r)$ - arithmetic average of the rate of return,

$E(f)$ - arithmetic average of the risk-free rate of return, $O(r)$ - standard deviation of rates of return.

- the average coefficient of volatility (ratio $x_{8}$ ) is the ratio of the average deviation of the arithmetic average multiplied by $100 \%$ and is expressed:

$$
V=\frac{s}{|E(r)|} \cdot 100 \%
$$

where:

$V$ - average coefficient of variation,

$s$ - average deviation of the rates of return,

$E(\mathrm{r})$ - arithmetic average of the rates of return.

- the average rate of return per transaction (ratio $x_{9}$ ), counted as the quotient of the rate of return and the number of transactions.

For the purpose of the comparison of the agents' performance, the following evaluation function was elaborated:

$$
\begin{aligned}
& y=\left(a_{1} x_{1}+a_{2} x_{2}+a_{3}\left(1-x_{3}\right)+a_{4} x_{4}+a_{5} x_{5}+\ldots\right. \\
& \left.+a_{6}\left(1-x_{6}\right)+a_{7} x_{7}+a_{8}\left(1-x_{8}\right)+a_{9} x_{9}\right)
\end{aligned}
$$

where $x_{i}$ denotes the normalized values of the ratios. Coefficients $a_{1}$ to $a_{10}$ may be also determined by the investor in accordance with his/her preferences (for instance, the user may determine whether is interested in the higher rate of return with a simultaneous higher risk level or lower risk level, but simultaneously agrees to a lower rate of return). These functions allow for determining the best strategies for the user in a given time period. Coefficients $a_{1}$ to $a_{10}$ can be used also for creating different users' profiles (allow for personalization of A-Trader). The function is given the values

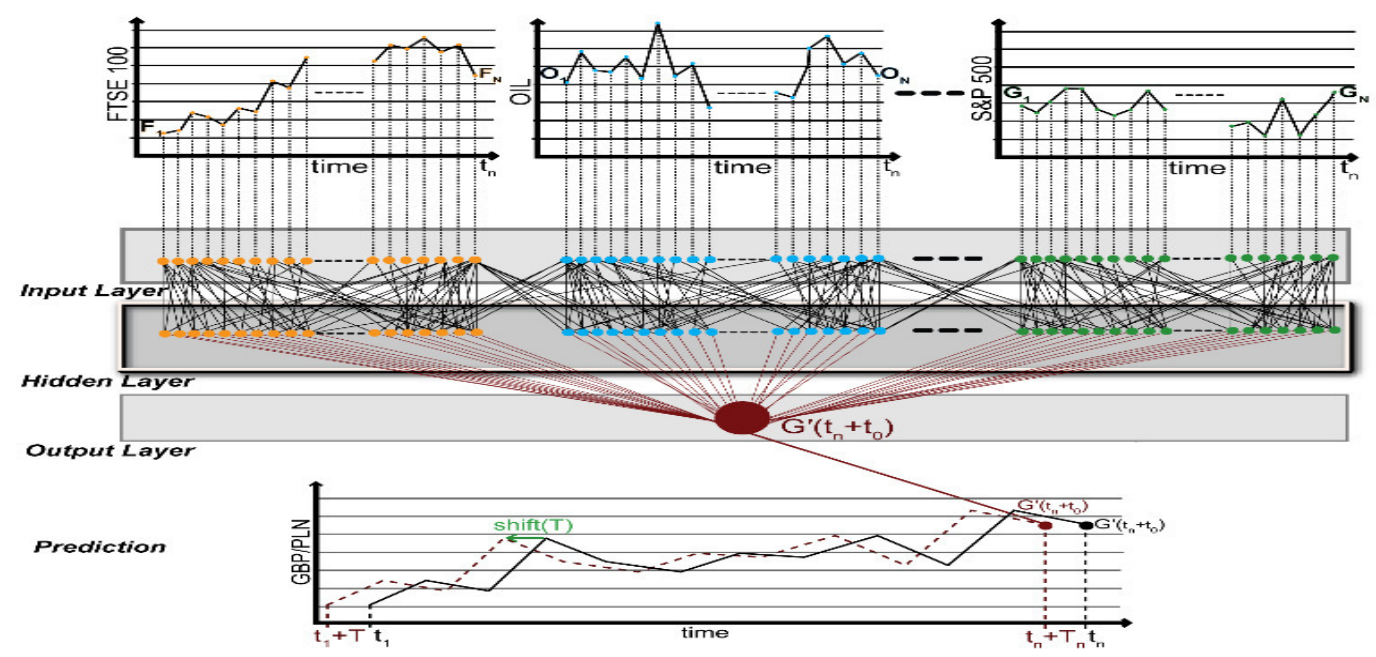

Fig. 2 Fundamental Analvsis Agent 
from the range [0..1], and the agent's efficiency is directly proportional to the function value.

\section{V.EXPERIMENTS}

The agent's performance analysis was carried out for data within the M1 period of quotations from the FOREX market. For the purpose of this analysis, the test was performed in which the following assumptions were made:

1. USD/GBP quotes were selected from randomly chosen periods (each - 1440 quotations), notably:

-15-03-2016, 0:00 am to 15-03-2016, 23:59 pm,

- 16-03-2016, 0:00 am to 16-03-2016, 23:59 pm,

- 22-03-2016, 0:00 am to 22-03-2016, 23:59 pm,

2. At the verification, the trading signals (for open long/close short position equals 1, close long/open short position equals -1) were generated by the strategies FundamentalStrategy and Technical Strategy.

3. It was assumed that decisions' probability levels for open/close position are determined by the genetic algorithm (on the basis of earlier periods).

4. It was assumed that the unit of performance analysis ratios (absolute ratios) are pips (a pip is equivalent to the final number in a currency pair's price).

5. The transaction costs were directly proportional to the number of transactions.

6. The capital management - it was assumed that in each transaction the investor engages $100 \%$ of the capital held at the leverage 1:1. The investor may define another capital management strategy.

7. The results obtained by the tested agents were compared with the results of the Buy-and-Hold benchmark (a trader buys a currency at the beginning and sells a currency at the end of a given period).

Table 1 presents the results obtained in the particular periods. In general, it may be noted that strategies generated not only profitable decisions. However, the rate of return cannot be the only measure taken into account in the performance evaluation. Very important are also other ratios, among other risk involved in the investment.

The evaluation function provides the fast choice of the best strategy. It may be noted that the values of efficiency ratios of particular strategies differ in each period. Values of this function oscillate in the range from 0.02 to 0.51 . Therefore use of this function allows for reducing the deviation of the values of the ratios.

The results of the experiment allow us to state that the ranking of strategies' evaluation differs in particular periods. In the first period, the TechnicalStrategy was the best strategy, the FundamentalStrategy was ranked higher than $B \& H$ benchmark. In the second period also the TechnicalStrategy was ranked highest, but FundamentalStrategy was ranked lower than $B \& H$. Considering the third period, it may be noted that the FundamentalStrategy was the best strategy, although the Rate of Return of this strategy was not highest.

The highest value of evaluation function of FundamentalStrategy (in third period) results from the highest Average Rate of Return per Transaction and low risk measures' values. The $B \& H$ benchmark was ranked lowest in two periods, and in the first and third periods it generated the losses. It should be noted that in the second period, the upward trend was observed, therefore $B \& H$ 's Rate of Return was positive. The first and the third periods show a downward trend, and therefore the $B \& H$ 's Rate of Return is negative. Taking into consideration all the periods, it may be stated that there is no one strategy ranked highest most often. Also, strategies achieving the highest Rate of Return were not always ranked in the highest positions. TechnicalStrategy always was characterized by greater number of transactions than FundamentalStrategy. However, FundamentalStrategy is characterized by highest Rate of Return per Transaction, than TechnicalStrategy. Both, TechnicalStrategy and FundamentalStrategy are characterized by low level of risk. This results mainly from the fact that these strategies take into consideration decisions generated by large numbers of agents.

During performing the experiments, a problem with neural network learning, was also observed. Values of the input

TABLE I.

PERFORMANCE ANALYSIS RESULTS

\begin{tabular}{|l|c|c|c|c|c|c|c|c|c|}
\hline \multirow{2}{*}{ Ratio } & \multicolumn{2}{|c|}{ FundamentalStrategy } & \multicolumn{2}{|c|}{ TechnicalStrategy } & \multicolumn{3}{|c|}{ B \& H } \\
\cline { 2 - 11 } & $\begin{array}{c}\text { Period } \\
\mathbf{1}\end{array}$ & $\begin{array}{c}\text { Period } \\
\mathbf{2}\end{array}$ & $\begin{array}{c}\text { Period } \\
\mathbf{3}\end{array}$ & $\begin{array}{c}\text { Period } \\
\mathbf{1}\end{array}$ & $\begin{array}{c}\text { Period } \\
\mathbf{2}\end{array}$ & $\begin{array}{c}\text { Period } \\
\mathbf{3}\end{array}$ & $\begin{array}{c}\text { Period } \\
\mathbf{1}\end{array}$ & $\begin{array}{c}\text { Period } \\
\mathbf{2}\end{array}$ & $\begin{array}{c}\text { Period } \\
\mathbf{3}\end{array}$ \\
\hline Rate of return [pips] & 9 & -66 & 28 & 56 & 132 & 48 & -143 & 89 & -160 \\
\hline The number of transactions & 4 & 7 & 5 & 39 & 52 & 42 & 1 & 1 & 1 \\
\hline Gross profit [pips] & 11 & 61 & 43 & 125 & 124 & 93 & 0 & 89 & 0 \\
\hline Gross loss [pips] & 17 & 37 & 28 & 65 & 81 & 49 & -143 & 0 & -160 \\
\hline The number of profitable transactions & 3 & 3 & 3 & 27 & 38 & 27 & 0 & 1 & 0 \\
\hline The number of profitable consecutive transactions & 2 & 2 & 2 & 11 & 6 & 4 & 0 & 1 & 0 \\
\hline The number of unprofitable consecutive transactions & 1 & 3 & 2 & 2 & 2 & 1 & 1 & 0 & 1 \\
\hline Sharpe ratio & 0.55 & 1.8 & 0,78 & 0.91 & 2.60 & 1.38 & 0 & 0 & 0 \\
\hline The average coefficient of volatility [\%] & 1.66 & 0.36 & 1.94 & 1.86 & 0.24 & 0.92 & 0 & 0 & 0 \\
\hline The average rate of return per transaction & 2.25 & $-9,43$ & 5,6 & 1.43 & 2.54 & 1.14 & -143 & 89 & -160 \\
\hline Value of evaluation function $(\mathbf{y})$ & $\mathbf{0 . 4 3}$ & $\mathbf{0 . 1 9}$ & $\mathbf{0 . 5 1}$ & $\mathbf{0 . 4 9}$ & $\mathbf{0 . 4 3}$ & $\mathbf{0 . 4 7}$ & $\mathbf{0 . 0 8}$ & $\mathbf{0 . 3 8}$ & $\mathbf{0 , 0 2}$ \\
\hline
\end{tabular}


vectors was very similar, thus learning process was not always convergent. It may result from long-time fluctuations of fundamental indicators in relation to short-time fluctuation of currencies quotations.

\section{CONCLUSION}

The fundamental analysis implemented as investment strategy in A-Trader can be used as confirmation of decisions generated by other strategies. However, investing only on the basis of FundamentalStrategy does not allow us to achieve a satisfactory rate of return. Often, fundamental analysis indicators are time-shift in relation to currency value (for example, changes in oil prices or S\&P500 quotations presented in fig 1 go faster than the USD/GBP trend). Thus, although we see on the chart a correlation between fundamental analysis indicators and currency quotations, the Mann-Kendall test has not confirmed this correlation, due to the time-shift. This implies the need for further research work on developing the fundamental strategy to take into consideration the time-shift phenomenon and on improving methods for neural network learning adjusted to fundamental indicators' values.

\section{REFERENCES}

[1] B. LeBaron, "Active and Passive Learning in Agent-based Financial Markets", Eastern Economic Journal, vol. 37, pp. 35-43, 2011.

[2] L. Mendes, P. Godinho and J. Dias, "A Forex trading system based on a genetic algorithm”, Journal of Heuristics 18 (4), pp. 627-656, 2012.

[3] J.R. Thompson, J.R. Wilson and E. P. Fitts, "Analysis of market returns using multifractal time series and agent-based simulation", in Proceedings of the Winter Simulation Conference (WSC '12). Winter Simulation Conference, Article 323, 2012.

[4] C. D. Kirkpatric and J. Dahlquist, Technical Analysis: The Complete Resource for Financial Market Technicians, Financial Times Press, 2006.

[5] C. Lento, "A Combined Signal Approach to Technical Analysis on the S\&P 500”, Journal of Business \& Economics Research, 6 (8), pp. 41$51,2008$.

[6] H. C. Aladag, U. Yolco and E. Egrioglu, "A new time invariant fuzzy time series forecasting model based on particle swarm optimization", Applied Soft Computing, 12 (10), pp. 3291-3299, 2012.

[7] P. Singh and B. Borah, "Forecasting stock index price based on Mfactors fuzzy time series and particle swarm optimization", International Journal of Approximate Reasoning, 55 (3), pp. 812-833, 2014

[8] O. Badawy and A. Almotwaly, "Combining neural network knowledge in a mobile collaborating multi-agent system", Electrical, Electronic and Computer Engineering, ICEEC '04, pp. 325, 328, 2004, DOI: 10.1109/ICEEC.2004.1374457.

[9] M. Aloud, E.P.K. Tsang and R. Olsen, "Modelling the FX Market Traders' Behaviour: An Agent-based Approach", in Simulation in
Computational Finance and Economics: Tools and Emerging Applications, B. Alexandrova-Kabadjova, S. Martinez-Jaramillo, A. L. Garcia-Almanza and E. Tsang (eds.), IGI Global, 2012, pp. 202228.

[10]P. R. Kaltwasser, "Uncertainty about fundamentals and herding behavior in the FOREX market", Physica A: Statistical Mechanics and its Applications, 389 (6), pp. 1215-1222, March 2010.

[11] J. B. Glattfelder, A. Dupuis and R. Olsen, "Patterns in high-frequency FX data: Discovery of 12 empirical scaling laws", Quantitative Finance, 11 (4), pp. 599-614, 2011.

[12]R.P. Barbosa and O. Belo, "Multi-Agent Forex Trading System", in Agent and Multi-agent Technology for Internet and Enterprise Systems, Studies in Computational Intelligence, vol. 289, 2010, pp. 91-118.

[13]F. H. Westerhoff, "Multi-Asset Market Dynamics", Macroeconomic Dynamics, 8/2011, pp. 596-616, 2011.

[14] S. Johnson, "Push to tap into EM currency returns", Financial Times, February 2011.

[15]A. Kritzer, "Forex For Beginners. A Comprehensive Guide to Profiting from the Global Currency Markets", Apress, 2012.

[16]J. Kumar, T. Rao and S. Srivastava, "Economics of Gold Price Movement-Forecasting Analysis Using Macro-economic, Investor Fear and Investor Behavior Features", in S. Srinivasa, V. Bhatnagar (eds.), Big Data Analytics, Lecture Notes in Computer Science, Volume 7678, Springer-Verlag, Berlin, Heidelberg 2012, pp. 111-121, DOI: 10.1007/978-3-642-35542-4 10.

[17] J. Korczak, M. Hernes and M. Bac, "Fuzzy Logic as Agents' Knowledge Representation in A-Trader System", in E. Ziemba (ed.), Information Technology for Management, Lecture Notes in Business Information Processing, vol. 243, Springer International Publishing, 2016, pp. 109-124.

[18]J. Korczak, M. Hernes and M. Bac, "Performance evaluation of decision-making agents' in the multi-agent system", in Proceedings of Federated Conference Computer Science and Information Systems (FedCSIS), Warszawa, 2014, pp. 1171 - 1180. DOI: $10.15439 / 2014 \mathrm{~F} 188$.

[19]M. Hernes and N.T. Nguyen, "Deriving Consensus for Hierarchical Incomplete Ordered Partitions and Coverings", Journal of Universal Computer Science 13 (2), pp. 317-328, 2007.

[20]M. Hernes and J. Sobieska-Karpińska , "Application of the consensus method in a multi-agent financial decision support system", Information Systems and e-Business Management 14 (1), Springer Berlin Heidelberg, 2016, DOI: 10.1007/s10257-015-0280-9.

[21]P. D. McNelis, "Neural Networks in Finance: Gaining Predictive Edge in the Market" (Academic Press Advanced Finance Series). Academic Press, Inc., Orlando, FL, USA, 2004.

[22]F. Ahrens, "U.S. Trade Imbalance Widens Slightly: So What?" Washington Post, May 2009.

[23] S. Johnson, "Push to tap into EM currency returns", Financial Times, February 2011.

[24]J. Beckmann, A. Belke and M. Kühl, "The dollar-euro exchange rate and macroeconomic fundamentals: a time-varying coefficient approach", Review of World Economics 147 (1), pp 11-40, 2011.

[25]P. Singh and B. Borah, "Forecasting stock index price based on Mfactors fuzzy time series and particle swarm optimization", International Journal of Approximate Reasoning, 55 (3), pp. 812-833, 2014.

[26]P. van Foreest and C. G. de Vries, "The Forex Regime and EMU Expansion", Open Economies Review, 14 (3), pp. 285-298, 2003.

[27] http://forexmarketexplained.com/ 